\title{
Automated Vehicle Handover Interface Design: Focus Groups with Learner, Intermediate and Advanced Drivers
}

\author{
Jediah R. Clark ${ }^{1} \mathbb{0} \cdot$ Neville A. Stanton ${ }^{1} \cdot$ Kirsten M. A. Revell ${ }^{1}$
}

Received: 25 February 2019 / Accepted: 21 November 2019 / Published online: 16 January 2020

(c) The Author(s) 2020

\begin{abstract}
Conditionally and highly automated vehicles will require drivers to take control as a result of a non-emergency, such as a geographical, terrain, capability or design boundary. It is anticipated that these events will provide the driver with a sufficient amount of time to prepare themselves for the transition of control. This study explores conditionally and highly automated vehicle transitions of control by asking how drivers of differing skill levels (learner, intermediate and advanced) approach the task of designing an interface responsible for making transitions safer, more usable and more efficient. Three focus groups generated detailed designs for vehicle-to-driver transitions in an 1-h and a 10-min "out-of-the-loop" scenarios and transitions from driver to vehicle. Results show great variation in the approaches taken by each skill group (e.g., the reliance on visual interfaces for awareness assist and viewpoints on issues such as multimodal displays). Customization was a common theme throughout, with drivers desiring the option to adjust alert timings and modalities in which information is displayed. This paper presents these designs along with a detailed comparison of group designs and implements distributed situation awareness theory to discuss findings and draw conclusions.
\end{abstract}

Keywords Handover · Takeover - Level 3 automation · Interface design · Automobile

$\begin{array}{ll}\text { Abbreviations } \\ \text { C/HAV } & \text { Conditionally and highly automated vehicle } \\ \text { DSA } & \text { Distributed situation awareness } \\ \text { HDD } & \text { Head-down display } \\ \text { HMI } & \text { Human-machine interface } \\ \text { HUD } & \text { Head-up display } \\ \text { OOTL } & \text { Out-of-the-loop } \\ \text { SA } & \text { Situation awareness }\end{array}$

\section{Introduction}

\subsection{Levels of Automation}

In automobile technology, the levels of automation [1] represent separate avenues that manufacturers can pursue in an attempt to be part of a driverless future. Each approach

Jediah R. Clark

jrc1g15@soton.ac.uk

1 Human Factors Engineering Team, Transportation Research Group, Boldrewood Innovation Campus, University of Southampton, Burgess Road, Southampton SO16 7QF, UK comes with its own set of benefits and drawbacks that require consideration during the design process. As defined by the SAE [1], "level 5" automation (full-automation) involves the removal of driving inputs, so that a physically present human is not required to take control of the vehicle. This stage is thought to require a larger investment from designers and manufacturers to ensure that autonomous vehicles can respond appropriately in any given situation on its route. Inevitably, the collective public attitudes and law will dictate the pace at which these vehicles are developed. Alternatively, conditionally and highly automated vehicles (C/HAVs) [2] could be on our roads sooner (Levels 3 and 4) [1] - that is, automation that either expects or may have the option (respectively) to handover control to the driver when approaching a geographical, terrain, capability or design boundary (level 3) or on request by the driver (level 3 and 4). This may be more feasible for manufacturers, as there is greater ability to apply automation selectively to less complex and more predictable scenarios, such as highway driving [3]. C/HAVs, however, come with their own challenges and risks that are to be addressed as they require human engagement as well as transitions of control and responsibility to achieve adequate driving performance [1]. 
Many automotive manufacturers are currently establishing their approaches to C/HAVs. With the release of Audi's current A8 model, it is now possible to have a driver relinquish control and strategic planning of the vehicle in traffic jam scenarios, allowing the driver to take part in secondary tasks (depending on legal frameworks within the region) [4]. This trajectory requires designers and manufacturers alike to consider transitions from secondary tasks back to the dynamic driving task.

\subsection{Handover Problem}

In high-risk domains such as medicine, air traffic control and energy generation and distribution, the "handover" represents vulnerability and poses risk to a system's operation, typically due to inadequate communication of information and intentions [5-7]. C/HAVs represent the vanguard of fullautomation, and much is yet to be understood regarding transitions to and from manual control in these vehicles. In their comprehensive review, Morgan et al. [8] outlined the current state of research in semi-automated handover alongside the human factors issues presented, such as a reduction in situation awareness (SA) due to being "out-of-the-loop" (OOTL) [9], poor calibration in trust- that is, seeking to design a system that provides information that represents the automation's true ability, thereby not facilitating misuse or disuse [10-13] and feelings such as frustration from a user perspective [14]. It has also been noted that issues such as mode error (mistaking that automation is either active or inactive) should be taken into account in automation human-machine interface (HMI) design - these factors may lead to implications related to safety, usability and the acceptance of automated vehicles $[15,16]$.

\subsection{Distributed Situation Awareness and C/HAVs}

Reductions in SA are well cited as a contributing factor toward incidents in many domains [9, 17-20], including those with automation capabilities. SA has developed greatly since its inception; the original description of SA proposed by Endsley [21] stated that SA represents the accurate perception, comprehension and projection of situational elements. However, many researchers and practitioners are now favoring a distributed cognition approach to the concept of SA-distributed situation awareness (DSA) [22, 23]. This is due to the recognition of complex socio-technical systems consisting of both human and non-human agents, each interacting with different perceptions and interpretations of the environment. From this perspective, it is the entire system that either gains or loses SA. This approach is beneficial as it acknowledges variation in individual "schemata" and role expectations that each agent brings to the task and demonstrates how information does not have to reside equally among every individual, as this information can be accessed when required in environmental artefacts, a concept that traditional models do not address.

For C/HAVs, the DSA approach may be particularly beneficial for the following reasons:

(1) Drivers and automation will inevitably hold different perspectives on the environment both due to previous activities and unique capabilities.

(2) C/HAVs will be able to process, feedback and potentially take control of aspects of the driving task (e.g., automatic braking) and direct the driver to hazards (e.g., visual and audio alerts) during all stages of the driving task, whether in primary control or otherwise.

(3) Information is provided to the driver not as a way of "sharing SA" but matched to the driver's unique capabilities and role, fostering what is known as "compatible SA" through "transactions" [24]. This may be a more appropriate approach to vehicle automation, as differences between humans and computers result in the requirement for information to be presented in line with a driver's cognitive abilities [25].

For C/HAV handover, regaining control from an automated system may lead to degraded driver performance as a result of deskilling or incompatible SA [22, 23, 26]. While automation is active, the driver is separated from the driving task; thus, emphasis should be placed on the interactions between automation and driver to ensure system SA is raised during vulnerable periods such as the handover of control.

To apply the insights generated by DSA, Salmon et al. [27] provided a number of recommendations when implementing DSA theory to a given system. For C/HAV handover, the following are deemed to be particularly pertinent and worthy of further discussion:

(1) SA requirements should be clearly specified as a result of careful analysis.

(2) C/HAVs should be designed to support SA transactions.

(3) Unwanted information should be removed.

(4) Interfaces should be customizable.

(5) C/HAVs should provide appropriate and explicit communication links.

(6) C/HAVs should use procedures to facilitate DSA.

\subsection{Driver Skill in C/HAVs}

DSA refers to Neisser's perceptual cycle model [28] to provide insights into how individual agents integrate with their environment, both perceptually and behaviorally. The model outlines that individuals make use of "schemata"-mental templates constructed from past experience that are accessed to interpret environmental cues and guides appropriate 
behavioral responses. In driving tasks, the idea of every driver possessing unique schemata as a result of past experiential and behavioral events raises an interesting questionHow do drivers of differing skill view the handover task in $\mathrm{C} / \mathrm{HAV}$ s? To begin answering this question, it is necessary to evaluate previous research on driver skill and behavior.

The relationship between the ability to raise individual SA and driver skill shows that advanced driver training may improve driver situation awareness [29]. Walker et al. [25] found that advanced driver training may improve working memory capabilities that result in the improvement in driver situation awareness. Advanced drivers have also been found to pay closer attention to environmental feedback [25, 30]. This addresses Neisser's perceptual cycle model [28] as driver behavior is guided by driver schemata (as a result of experience) and becomes more sensitive to environmental cues. For this reason, it could be predicted that advanced drivers may not require comprehensive handover assistants, as they are more capable of processing environmental information and raise their own individual SA without the need for complimentary interfaces. This is further illustrated by findings presented by Young and Stanton who found that there was an effect of driver skill on the issue of workload in automated driving [31, 32]. Young and Stanton [32] summarized their findings with reference to the malleable attentional resources theory [31-33] as an illustration of the inverse relationship between driver skill and mental workload [34]. As skill increases in the driving task, so does automaticity. Further, research into new drivers and hazard perception shows a range of differences to their more experienced counterparts such as less-efficient gaze behavior, less vigilance regarding their mirrors and closer focus on the front of the vehicle $[35,36]$. It may be that drivers of less experience will benefit from handover awareness assist more due to their attentional shortcomings as learners.

Advanced driver courses are intensive and typically occur over a number of days. Training involves understanding why accidents occur, managing risks, understanding how human factors affect performance and improving observations, which is finalized with a test.

Driver experience and driver age are inherently correlated. Arguably, with age come changes in the way the driving task is performed, and studies looking into driver skill are inevitably confounded by this variable, a factor recognized across driving research [37]. In controlled experiments exploring takeover performance and age, Körber et al. [38] found little differences in behavioral performance when drivers were asked to take control with and without a secondary task. Morgan et al. [8] argued that most handover studies focused on mainly middle-aged and high-mileage drivers. As interaction with automation is dependent on driver skill [33], it is important to consider the future of C/HAV operation for the range of driver skill groups. In the current state,
C/HAVs will be implemented in vehicles with high prestige. However, over time, $\mathrm{C} / \mathrm{HAV}$ s will become more accessible to a wide range of drivers with differing skills and experience. It may be that advanced drivers, equipped with their experience, will be more comfortable taking control from a $\mathrm{C} / \mathrm{HAV}$ as they are familiar with the nature of the roadway; however, a learner would have had less exposure to such events.

\subsection{Current State of Handover Assistants}

C/HAVs differ from their predecessors in their potential for allowing drivers to take their eyes/mind off the road. This study directly addresses this, and the implications they ensue (see Sect. 1.2) by exploring how "handover assistants" could aid in the transition of control. In their comprehensive review in transition interfaces, Mirnig et al. [39] outlined the current state of transition interfaces in regard to a categorization framework. The authors identified contributory work across academia and industry. Notable design specifications from this review include: (1) alerts informing of situation and takeover time [40], (2) implementing bimodal (auditory and visual) takeover requests [41], (3) exploring multimodal alerts and the effect of direction on takeover performance [42], (4) ambient and contextual cues to facilitate takeover [43], (5) graded takeover request in "soft takeover request" scenarios [44] and (6) multimodal alerts in relation to urgency [45].

As an example, Naujoks et al. [46] provided a prototype handover interface that gives the driver information about the current situation prior to taking control. Elements include the speed of the vehicle, the type of road event that is causing the handover and distance to the event. The request is displayed in two different ways: non-imminent (middle panel) with banners colored in orange, with a wheel indicating how much time remains for takeover to occur, and imminent (right panel) with banners colored in red and a more urgent message. Their interface recommendation follows concept-related cooperative perception technology [47], which involves interfaces feeding real-time, eventcritical information to the driver to improve safety following a takeover request.

\subsection{Case for Extended Handover Preparation in a Non-Emergency}

Emergency takeover scenarios do not typically give the driver a time allowance to raise SA as a result of "OOTL performance." Conversely, when boundaries, such as geographical or design capabilities (e.g., road works, exiting junction on motorway to urban area), are predictable, time is likely to be more readily available. As Patterson and Woods stated, the handover is a time when the incoming operator 
must raise SA and have a complete mental model of the situation and anything that has changed [48].

\subsection{Current Study and Research Questions}

The authors propose that experimental iterations, while important, limit the scope and potential of targeting user requirements in a timely fashion. It is therefore deemed necessary to consider other rigorous research methods that target the core of usability principles. Participatory design is an approach to a design problem that seeks to include the end user in the design process, thus addressing their needs and concerns at the beginning of the design life cycle [49]. It stems from the philosophy that users have valuable insights that can lead to creative concepts when given the chance to share their ideas [49]. The challenge arises for designers to take user experience and participatory designs and implement them with practical, realistic and balanced approach [50]. A good illustration of this concept is the implementation of customization and personalization in designs [51, 52]. Customization, by definition, allows users to individually tailor preferences/requirements to their own individual needs [53] but should lie within scope of design specifications and legislature. On the other hand, personalization relates to the profiling and creation of a design that can be applied to a target group [54]. Both approaches appear to have individual merit; however, understanding how both can be implemented requires a sufficient amount of knowledge about user needs and requirements [50].

Although qualitative in nature, participatory design focus groups allow quick insight into user requirements [55] and provide high quantities of rich information suitable for fastpaced fields such as automotive automation. The domain of $\mathrm{C} / \mathrm{HAV}$ handover lends itself to the participatory design approach due to the availability of a range of demographics available to researchers as drivers are part of the general public. This study implements the participatory design approach by asking groups of drivers to discuss and design a C/HAV handover and handback assistant. The following research question is central to discussions: how do drivers of different skill categories view solutions to the handover and handback problem in $\mathrm{C} / \mathrm{HAVs}$ ?

\section{Method}

\subsection{Participants}

Ethical approval was gained via the University of Southampton ethics panel (ERGO II No. 40182). Drivers were recruited across three separate categories as defined by Young and Stanton [33]: (1) learner drivers-currently having lessons, (2) intermediate drivers-drivers who have held a full-license for over 1 year and (3) advanced drivers-having completed an advanced driving course under the Institute of Advanced Motorists (IAM) [56] or the Royal Society for the Prevention of Accidents (RoSPA) [57].

Due to availability and population demographics, balancing age and gender was challenging (e.g., learner drivers more likely to be young, advanced drivers likely to be older males). These confounding variables are well noted across driving research [37].

Focus groups consisted of between five and seven participants, conforming to the size of focus groups outlined by Krueger and Casey [58, 59]. Participant data are displayed in Tables 1 and 2 showing demographics and driving experience.

\subsection{Design}

Focus groups lasted approximately one and a half hours in line with common practice [60]. Driver skill was implemented as a between-group, three-level independent variable categorized into groups of learner, intermediate and advanced drivers. Additional variables measured from the sessions were: age, gender, annual mileage, years holding license (and where applicable, hours of lessons and years of holding advanced qualification). Dependent variables from this study were the output from audio data and collective written design suggestions using post-it notes on a pre-designed template.

\subsection{Procedure}

Participants were recruited either via the University of Southampton's internal web-page (targeting learners/intermediates), through driving schools/instructors (targeting learners) or through both the Institute of Advanced Motorists [56] and the Royal Society with the Prevention of Accidents groups [57] (targeting advanced). Prior to taking part in the focus group, each participant filled out a demographic questionnaire. An introduction was given by the primary researcher to inform participants of the current state of $\mathrm{C} /$ HAVs, the challenges faced by designers (i.e., situation awareness, usability and trust) and the interface elements that are available to designers in current $\mathrm{C} / \mathrm{HAV}$ s such as head-up and head-down displays, vocal assistants, audio cues, haptic feedback and inputs. Following this, groups

Table 1 Participant demographics

\begin{tabular}{llll}
\hline Skill category & Number & Gender $(\mathrm{M} / \mathrm{F})$ & Mean age \\
\hline Learner & 7 & $4 / 3$ & $26.1(\mathrm{SD}=6.4)$ \\
Intermediate & 6 & $1 / 5$ & $52.6(\mathrm{SD}=16.8)$ \\
Advanced & 5 & $3 / 2$ & $63.3(\mathrm{SD}=7.2)$ \\
\hline
\end{tabular}


Table 2 Participant driving experience

\begin{tabular}{lllll}
\hline Skill category & Mean annual mileage & Mean years held license & Mean learner hours & $\begin{array}{l}\text { Mean years as } \\
\text { advanced driver }\end{array}$ \\
\hline Learner & - & - & $52.6(\mathrm{SD}=39.7)$ & - \\
Intermediate & $6500(\mathrm{SD}=3500)$ & $32(\mathrm{SD}=15.6)$ & - & - \\
Advanced & $12,600(\mathrm{SD}=2191)$ & $47(\mathrm{SD}=9.4)$ & - & $18.3(\mathrm{SD}=10.6)$ \\
\hline
\end{tabular}

were then given three storyboard scenarios, which were then addressed in sequence.

In scenario 1, participants were asked to discuss and generate design concepts related to being 1-h OOTL. The scenario described a driver manually driving through an urban environment and joining a highway. Upon joining the highway, automation was activated, and the driver took part in a range of secondary tasks such as emailing and playing games on a tablet. After $1 \mathrm{~h}$, the driver was expected to take control of the vehicle. Participants were at this time asked to discuss how they would want to be alerted, how information should be presented and how they desired the handover to take place. Scenario 2 followed an identical structure, with the change of 1-h OOTL to 10-min OOTL. Scenario 3 asked participants to think about the event in the last two scenarios where the driver joined the highway and automation was available. They were asked how the interfaces should communicate with them that automation was available and how they desired automation to be activated at this time.

Participants discussed their thoughts in relation to their driving experiences and a range of factors that they could consider including modalities (e.g., audio, visual), types of displays (e.g., head-up/head-down display), and timings, and were asked to generate information types and how they're delivered as a group, using their collective experiences concurrently, in the center of the room. The facilitator's role during discussions was to ensure that timings were met, and write up the group's ideas on post-it notes as well as prompt participants as to what information stream they desired each process to be allocated to, if not already specified.

\subsection{Method of Analysis}

The data from this study were derived from demographic information, design concepts and audio recordings. For each suggestion that the group agreed upon (as derived from audio recordings and written task), a schematic was digitally generated for each group as outlined in their written design concepts. A thematic analysis of transcripts was conducted to determine what aspects of handover protocol each group focused on during discussions-attributions made by two analysts of a random selection of suggestions (comprising $40 \%$ of total suggestions) agreed on $83.3 \%$ of statement-theme parings, exceeding the widely accepted minimum requirement for agreement [61].

\section{Results}

Figure 1 displays the frequency of design suggestions made by drivers during focus groups regarding the handover (driver to vehicle) in relation to five main themes. Themes were generated by the grouping of each suggestion $($ Learner $=18$, Intermediate $=14$, Advanced $=16)$ :

- Alert Any suggestion made that relates to the driver being made aware that a handover is required (e.g., audio tone and flashing light on dashboard).

- Check Arousal Any suggestion made that relates to the vehicle assessing the physical and/or cognitive arousal of the driver, whether through requests to actively respond, or implicit methods such as built in eye tracking.

- Choreography Any suggestion made that relates to timings, coordination or clarity of the handover process. Examples include the state of automation, and the time left until handover is expected.

- Aid Awareness Any suggestion made that indicates a requirement for the vehicle to feed information to the driver related to the past, present or future state of the

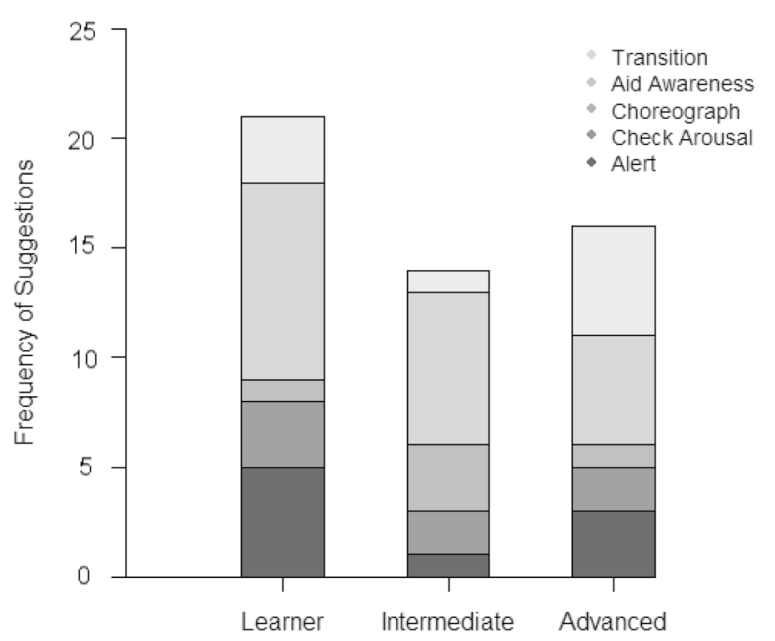

Fig. 1 Frequency of suggestions comparing the themes "aid awareness" and "transition" among driver skill groups 
driving scenario. Examples include hazards and route planning information.

- Transition Any suggestion made that relates to the physical aspect of taking over control of the vehicle (e.g., taking control of pedals before steering wheel).

Figure 1 shows that discussions in the learner group focused more on alerts and awareness assist, whereas as driver experience increased, a shift away from awareness assists toward designing better and smoother ways of transitioning control were observed. To understand these differences better, each group's final designs and comments are discussed in detail in the following sections.

\subsection{Learner Handover Design}

Figure 2 displays the design schematic created by the learner drivers' group. Overall, this group preferred visual interfaces to guide handover interactions. Starting with a vibrating seat "3 to 5 min before takeover was expected," notifications would steadily increase as the takeover time drew nearer. Vocal and audio notifications (e.g., polite tone or vocal instruction) would reduce radio volume and interacted with electronic devices that may be in use (e.g., smartphone). The group thought it would be important for the alerts and timings to be specific to the secondary task that was being performed (e.g., emailing, reading and conversing). From here, the driver provides an input to verify they are aware that they are required to take control.

During the information stage, the group thought it would be important to receive real-time information about where they were, and what the situation was like up ahead. GPS info was expected to be displayed on a center console, with augmented traffic information on the head-up display (HUD). Customizable vocal output was also desired at this stage. Concurrently, the group wanted information such as current gear and current speed displayed on the HUD, and any dangerous weather information to be displayed both on the head-down display (HDD) and HUD. From here, drivers wanted a way to raise awareness of what was around them through the use of surround cameras and blind spot indicators. Finally, prior to the takeover process, the group requested a way to reset driving position (seat and wheel position) to that of driving rather than secondary task; however, in a level 3 vehicle this may not be feasible due to the potential for an emergency takeover.

To take control, the learner focus group wanted an input in button form, due to its reliance, and a clear signal that control is now in the hands of the driver. Further, this group requested that automation would oversee their driving performance following handover. Throughout both automated and manual control, drivers requested that the HDD, when it was in automated mode, showed a clear color tint of the display (e.g., amber for manual, green for automated). Finally, while in automated mode, this group requested there to be a timer presented on the HUD indicating when driver control was expected, and a manual override capability.

For shorter journeys, the group found it to be important to customize the amount of time that is given for alerts to be given. It was widely thought that for a 10-min automation period, 1 min was sufficient to be alerted, raise SA and regain control. In regards to interfaces, the group decided that a lot can change in 10 min and kept the same design as the 1-h OOTL scenario.

\subsection{Intermediate Handover Design}

Figure 3 displays the design schematic created by the intermediate drivers' group. Overall, this group preferred visual interfaces in tandem with a vocal interface to guide handover interactions. The group discussed how they want the vehicle to have a typical cluster (speedo, RPM, fuel, engine temperature). Starting with the radio volume being lowered, the group requested a "non-threatening" jingle or tone to be presented that increased in intensity over time. Next, they wanted information displayed on the HDD, HUD and vocally to notify them of how long they have left, customized to 5 or 10 min prior to takeover. In tandem, the group requested distance left until takeover was expected, alongside any route, journey and traffic information displayed both on the HDD and vocally.

For the information stage, the group decided on having the different input options to either override (directly to takeover control) or receive awareness information. At this stage, if the driver has yet to respond, the seatbelt will pulse and the seat vibrates. The group then requested: (1) upcoming traffic or queues at the junction to be displayed both on the HUD and vocally, (2) fuel state and potential refill stations to be displayed should it be of importance, (3) other vehicles and hazards to be highlighted on the HUD that the driver can cancel should they wish and (4) weather and road condition information to be displayed on the HDD as well as ambient lighting to match (e.g., green for good conditions and red for dangerous conditions).

To takeover, the group felt it necessary to have a countdown on both the HDD, HUD and vocal interfaces in a $300 / 200 / 100$ yard fashion. At this point, the group felt it necessary to have two inputs on the steering wheel that are activated at the same time to avoid accidental deactivation of autopilot. This as well as pedal input and gaze detection are designed to show that the driver is ready to take control of the vehicle.

During the entire process, the intermediate focus group requested a way of asking the vehicle to repeat the last piece of information, as well as a way of overriding automation and taking control instantly. Further, to make sure 
Learner Handover Design

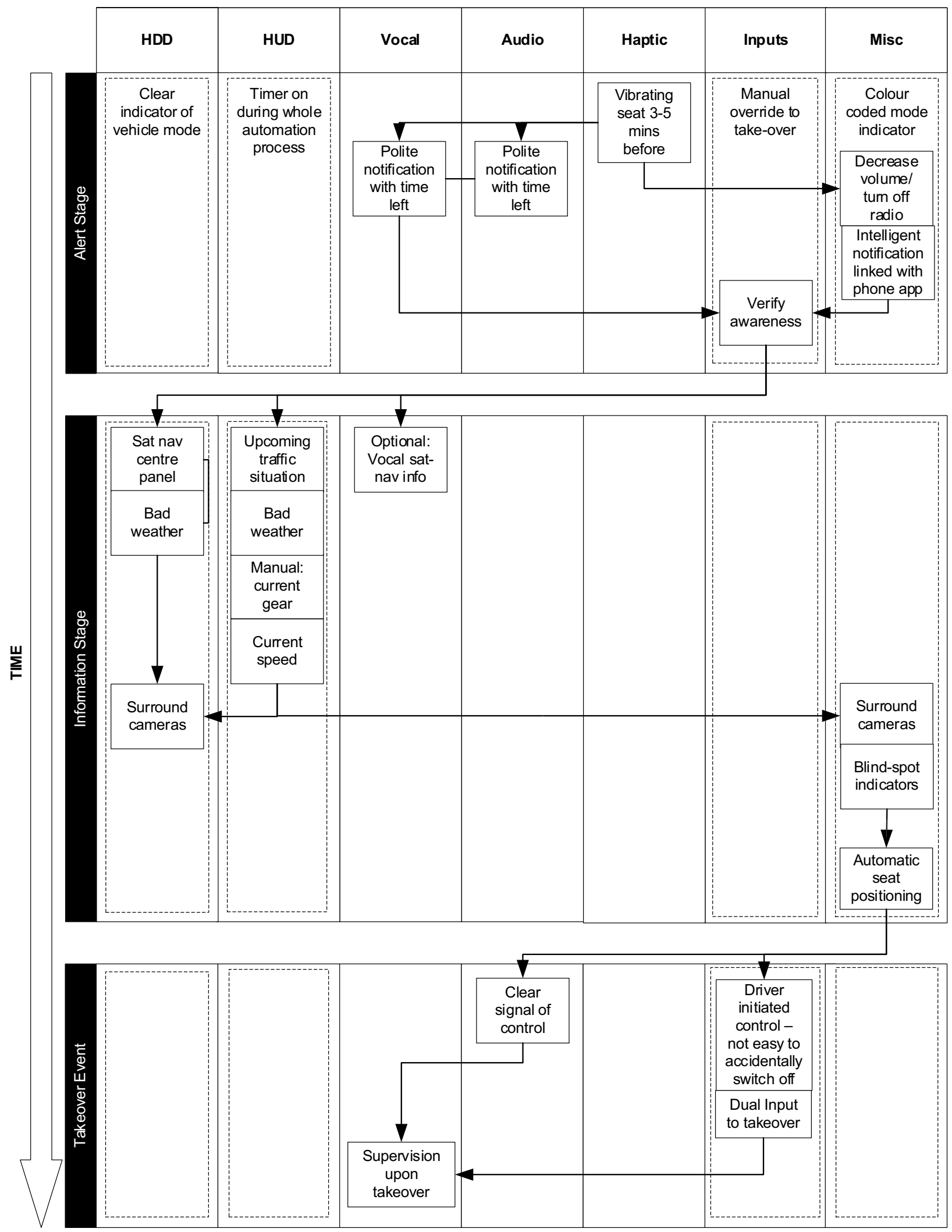

Fig. 2 Handover design from the learner driver group. Lanes indicate modality, nodes indicate type of information. Vertically connected/ adjacent nodes indicate concurrent presentation. $Y$-axis indicates time. Dotted boxes indicate that the node applies throughout the entire handover procedure 


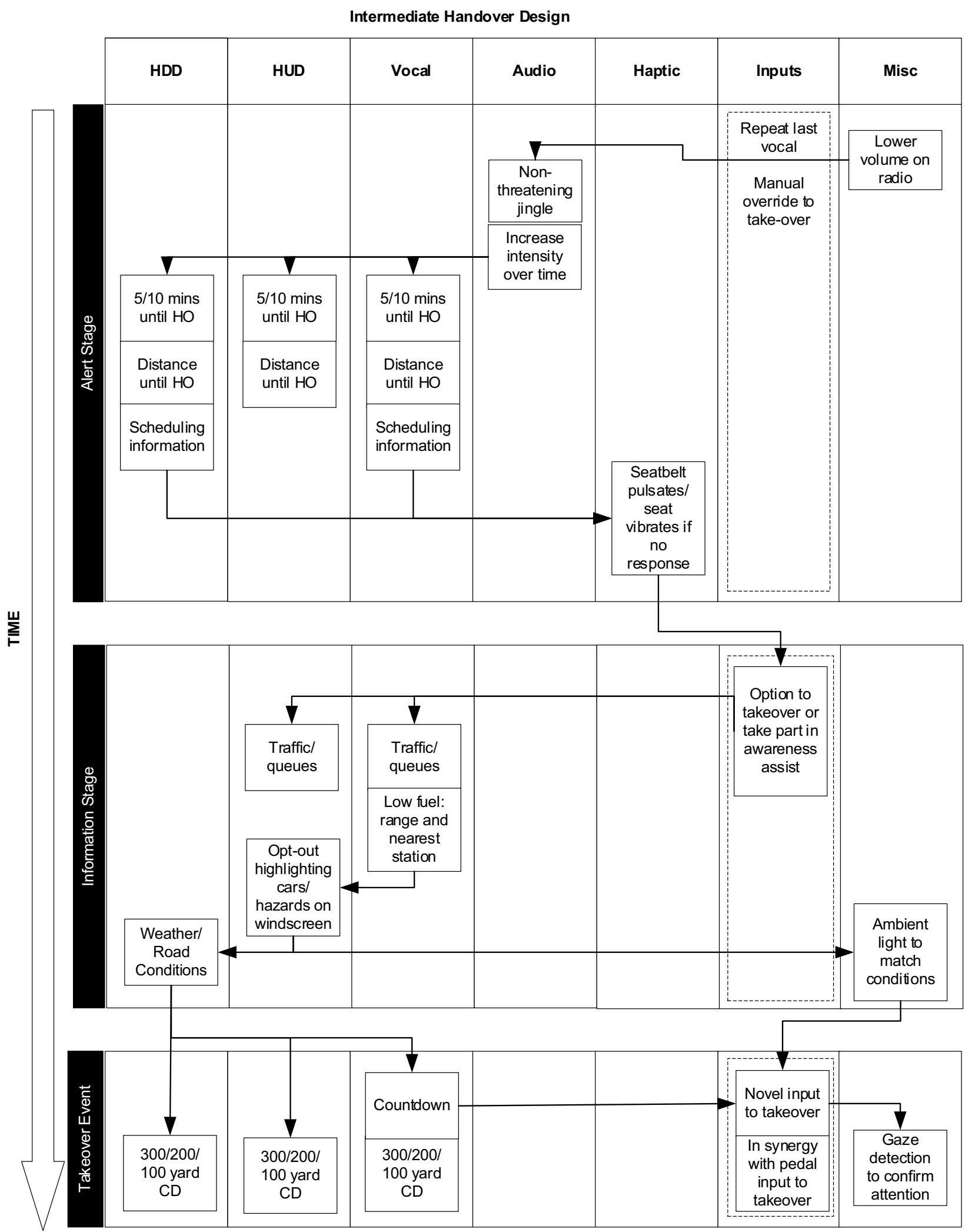

Fig. 3 Handover design from the intermediate driver group. Lanes indicate modality, nodes indicate type of information. Vertically connected/adjacent nodes indicate concurrent presentation. $Y$-axis indi- cates time. Dotted boxes indicate that the node applies throughout the entire handover procedure 
the handover does not surprise drivers, the group requested the ability to be able to input new directions or plans to the vehicle while it is in automated mode. Finally, customization was important for this group, specifically, in relation to confounding factors such as children in the car interfering with vocal assistants, this group requested a customization system for which modalities are used, and it is tailored to those who have particular accessibility requirements.

The intermediate group believed it to be unimportant to have any awareness assist or dangerous weather and road conditions displayed to them for shorter journeys. They suggested a 2-min warning for $10 \mathrm{~min}$ in automation-potentially calculated based on percentage of total automation time, which is vocally communicated once and is then followed by an HUD countdown display in time.

\subsection{Advanced Handover Design}

Figure 4 displays the design schematic created by the advanced drivers' group. Overall, this group preferred smooth transitions of control with little information displayed with regard to awareness assist, starting with a "quiet sound" that increases in intensity as time goes on, alongside a flashing light to show that the car expects a takeover soon. If no response is given, the seat would vibrate. To respond to automation, this group preferred to vocally communicate the message that they are ready.

For the information stage, the advanced group wanted ice information displayed on the HUD and communicated vocally, as well as vocal indication as to current location and upcoming situation (junction). At this stage, this group requested blind-spot indicators to be active. Next, opt-in

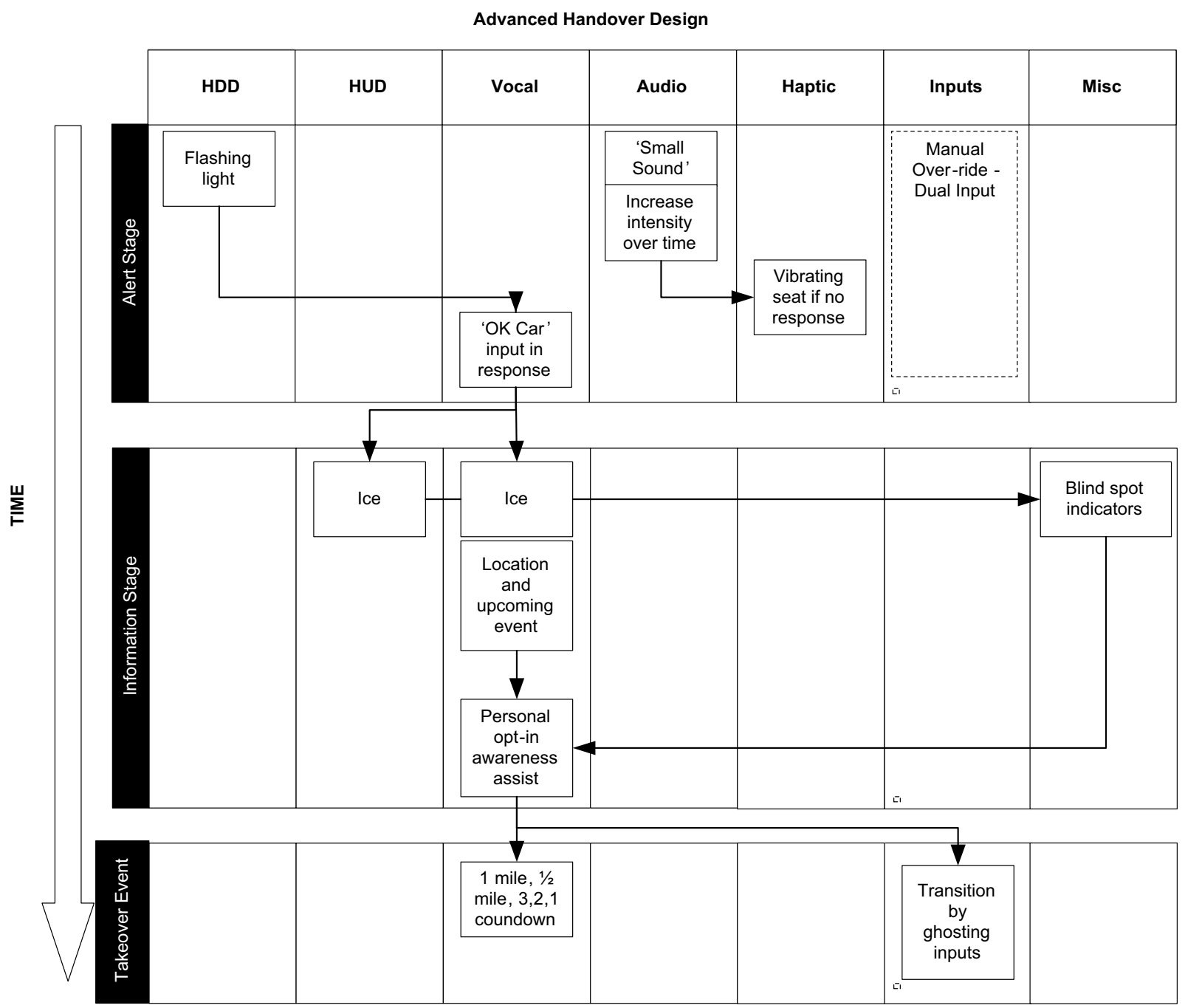

Fig. 4 Handover design from the advanced driver group. Lanes indicate modality, nodes indicate type of information. Vertically connected/adjacent nodes indicate concurrent presentation. $Y$-axis indi- cates time. Dotted boxes indicate that the node applies throughout the entire handover procedure 


\section{Collated Handback Designs}

\begin{tabular}{|c|c|c|c|c|c|c|}
\hline HDD & HUD & Vocal & Audio & Haptic & Inputs & Misc \\
\hline $\begin{array}{c}\text { Pages } \\
\text { showing route } \\
\text { info \& car } \\
\text { awareness }\end{array}$ & $\begin{array}{l}\text { Timer for } \\
\text { expected } \\
\text { handover }\end{array}$ & & $\begin{array}{l}\text { Universal } \\
\text { tone to show } \\
\text { automation is } \\
\text { available }\end{array}$ & & & \\
\hline $\begin{array}{l}\text { Car's future } \\
\text { actions (1 } \\
\text { minute) }\end{array}$ & & & & & & \\
\hline $\begin{array}{l}\text { Green } \\
\text { indicator to } \\
\text { show it's safe } \\
\text { to transition }\end{array}$ & & & & & & \\
\hline 7 & 7 & & & 7 & & \\
\hline $\begin{array}{l}\text { Symbol/ } \\
\text { colours } \\
\text { appear to } \\
\text { show it's in } \\
\text { autopilot }\end{array}$ & $\begin{array}{l}\text { Symbol/ } \\
\text { colours } \\
\text { appear to } \\
\text { show it's in } \\
\text { autopilot }\end{array}$ & & & $\begin{array}{l}\text { Slackening of } \\
\text { inputs as cue } \\
\text { of not in } \\
\text { control }\end{array}$ & & \\
\hline
\end{tabular}
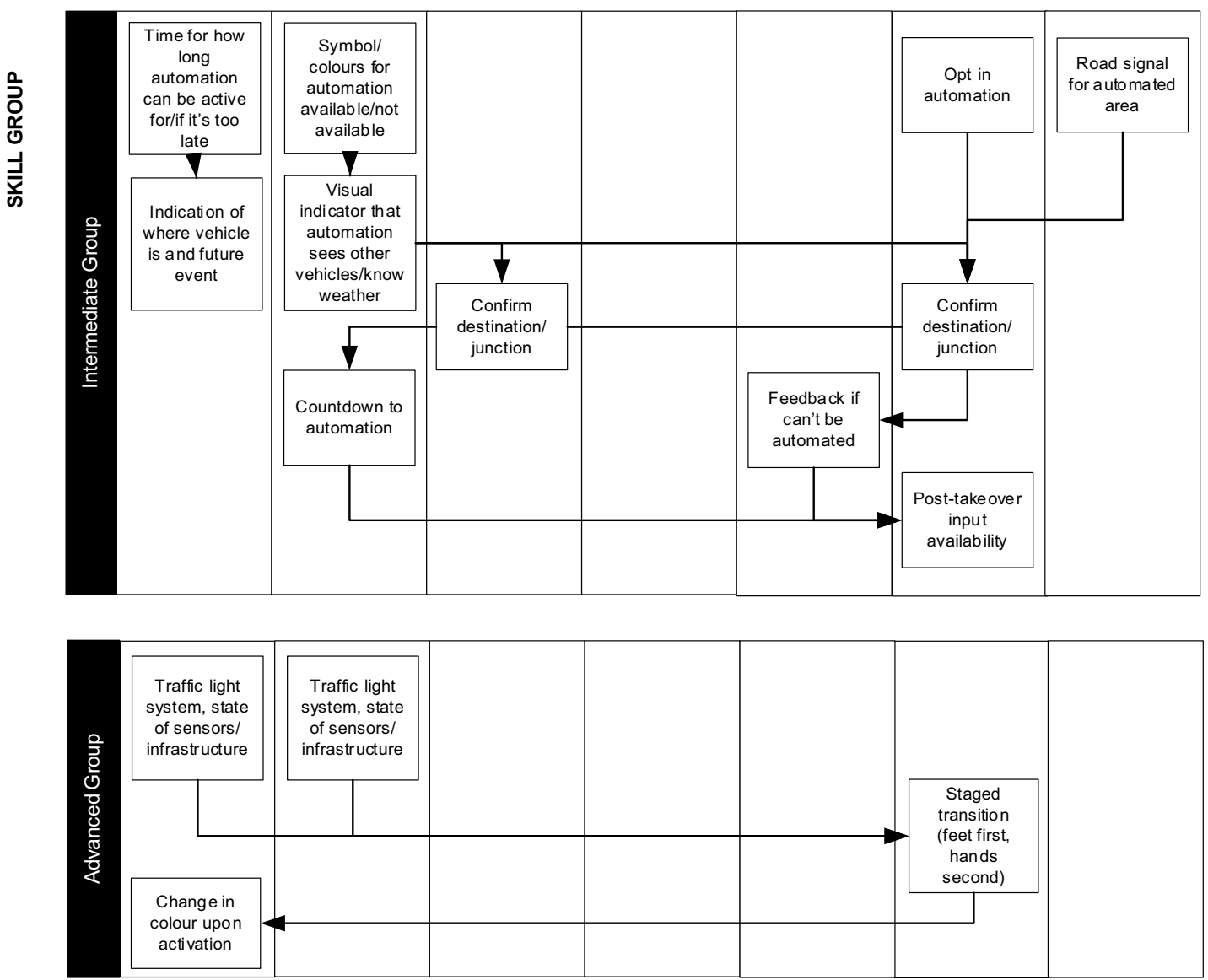

Fig. 5 Handback designs for each driver group. Lanes indicate modality, nodes indicate type of information. Vertically connected/adjacent nodes indicate concurrent presentation. $Y$-axis indicates group 
customized awareness assist (e.g., HUD/vocal) was suggested but not forced upon the driver.

To make the transition, this group suggested that the driver could drive the vehicle for a specific amount of time, without actually having control, once this was done for a set amount of time, the vehicle would know that the driver knows what they are doing and would transfer control with a vocal countdown (i.e., 1 mile, 1/2 mile, 3, 2, 1).

Just like the other groups, the advanced driver group made it clear that they would like a manual override in the form of dual-inputs, as well as customizable profiles for handover assist suited to the driver and the secondary task to be performed.

There was little comment by the advanced driver focus group as to how they'd change the handover process given the amount of time out of automation. However, they made it clear that they require an instant takeover input and that the process should not be "too long."

\subsection{Handback Designs}

Figure 5 displays the handback designs outlining how groups approached the action of transferring control back to automated driving. Generally, handback designs considered driver trust with the automated system and the physical action of transferring control. Groups differed in their approaches.

\subsubsection{Learner Group}

The learner group preferred to have a universal audio tone and the amount of time of automation available displayed in the HUD. Concurrently, they requested pages in an HDD console to show route info, the awareness the car has of the environment and the car's future actions so that "faith" can be built up prior to activation. Next, a green indicator is to be displayed on the HDD indicating a safe transition. Finally, symbols and colors are to be displayed across HDD and HUD to show the transition of control to automation as well as the slackening of controls.

\subsubsection{Intermediate Group}

The intermediate group suggested a more interactive handback design involving a range of driver inputs. To begin, this group desired physical road signs indicating that automation can be safely activated within a certain region. In the vehicle, they wanted the amount of time that automation can be active to be displayed on the HDD alongside colors and symbols on the HUD indicating that automation is available. The group made it clear that they wanted automation to support an opt-in approach. Following this, this group requested for the HDD to display information showing that the vehicle knew where it was and what it was going to do in the future (e.g., turn-off and handover). Concurrently, on the HUD, visual indicators that the vehicle is aware of, processing the movements of other vehicles as well as weather conditions, were requested. Before giving control, this group requested the option to confirm destination and junction through vocal interaction with the vehicle (input and feedback). Following the input of taking control, this group requested a countdown before control is handed back, and feedback through vibrations if the automation is not able to be activated. When control is given to automation, this group wanted communication to continue through the use of button inputs.

\subsubsection{Advanced Group}

The advanced group favored a simple approach to the handback, a clear indication of whether it's safe to activate represented by a traffic light system (representing sensors and infrastructure status), on the HDD and HUD. They requested for the transition to automated control to be staged starting with pedals, and then with the steering wheel, to gradually build trust. Finally, a change in color across the HDD indicates that automation is now in control.

\section{Discussion}

This study explored how drivers of differing experiences envisaged handover assistants with the intention of promoting safety while being usable and calibrated to suitable levels of trust. This was done through the use of focus groups to explore in detail how drivers viewed the issue of handover while being out-of-the-loop for differing periods of time $(1 \mathrm{~h}$ vs. $10 \mathrm{~min}$ ) as well as how control should be handed back to automation.

\subsection{Comparison of Groups' Handover Designs}

As the intermediate and advanced group were similar in mean age (52.5 and 63.3, respectively), comparisons can be made more easily between focus group designs. Overall, the advanced driver group expressed less reliance on the HMI for awareness and strategic planning and focused more on the transition itself. By way of contrast, learner and intermediate drivers expressed a preference for HDD, HUD and vocal interactions to raise awareness and guide the handover. As driver SA has been shown to be related to advanced driver training [22,29], it seems plausible that advanced drivers expressed a greater willingness to detect and process environmental cues themselves $[22,30]$ without the assist of a handover HMI (e.g., "Keeping my eye on the road at a certain time... so if I need information, it'd have to 
be projected onto a windscreen-but I'm not sure I need all of that information;" advanced group, participant 2).

As automaticity and workload are related to driver skill [33], learner and intermediate drivers may be more reliant on multiple streams of information such as concurrent displays for handover notifications when compared to their advanced counterparts (learners - traffic and location data on HDD, HUD and vocal; intermediates-notification and route data displayed on HDD, HUD and vocal, e.g., "maybe you have something... you feel something, then you see something and then you hear something"; learner group, participant 5). This is supported by research showing a reduction in perceived mental workload and greater user preference with the presentation of multimodal feedback $[62,63]$. This finding also supports previously proposed handover HMIs and the effectiveness of multimodal vehicle-initiated takeover requests $[41,42,45]$.

Perhaps the most discussed topic across all groups was the need for customization, a topic previously explored by Bazilinskyy and his colleagues $[64,65]$. The concept of customization in this study centered primarily on the modality in which information is displayed to the driver (e.g., "Well, I know I've got two kids in the back, and they're going to be singing or something,... So vocal things aren't going to cut it today"; intermediate group, participant 4), but also on how much time in advance drivers were alerted for the purpose of concluding secondary tasks or time OOTL (e.g., "I know I'm waiting on an important email, no matter what time you wake me up, I'm going to have to somehow finish it, and slam down my laptop, so I want 2 miles notice, not one"; advanced group, participant 3; "you're going to Romsey (from Southampton) you set the timer to $1 \mathrm{~min}$, and if you go to Newcastle you set it to 3 to 5 min"; learner group, participant 5). However, recommendation of what default, safety-critical settings should be communicated by the advanced group (e.g., "Well, then the default state needs to be safety"; participant 4 , advanced group). Solutions across the groups involved being able to make changes to the handover protocol prior to setting off for a journey in the form of a system that allows for pre-set and customizable profiles (e.g., "Well, maybe there should be different modes. One that has the voice, one that has haptics, and then one where it has haptics and lights, and written stuff"; learner group, participant 6).

All groups requested a way for the transition to require more than one input to avoid accidental deactivation, for example, the intermediate group suggested two sensors on the steering wheel in concurrence with detection of pedal inputs before automation can be deactivated. All groups requested information about where they were and what was coming up, either in the form of HUD augmentation coming up to junction, or as a regular sat-nav implemented on the console.

\subsection{Changes Following Shorter Time OOTL}

There has been little research regarding time OOTL and the changes to be made regarding its effect on handover performance from automation to human operator. Typically, the energy production domain favors allocating more time to handover if the incoming staff has been absent for a longer period of time $[66,67]$. There is a clear need in this domain to commit more resources to the handover task when time OOTL is higher. This study explored this concept in the automated vehicle handover task and asked what drivers may want to change in a handover HMI in the scenario of $10 \mathrm{~min}$ versus $1 \mathrm{~h}$.

Most of the discussion regarding time OOTL in both the learner and the intermediate group surrounded the amount of time prior to the takeover that alerts were given. Learners requested shorter journeys to give a 1-min warning (e.g., "I think the timings could be shorter, if it's only $10 \mathrm{~min}$ you don't need a 3 min warning"; learner group, participant 3), whereas intermediates preferred a more sophisticated system that calculates a percentage of the time OOTL for the amount of time given prior to takeover (e.g., "Percentage based on time overall for planned automation"; intermediate group, participant 3). The learner group kept their information streams the same, whereas intermediates stated that it wasn't important to have either awareness assist or information about weather/road conditions (e.g., "No no, I don't think you'd need it"-in response to question about awareness assist; intermediate group, participant 1). It may be that learners, with less skill, have a greater need for awareness assist, which is supported by research showing a decreased ability to detect hazards [35, 36]. Advanced drivers made no changes to their interface design; however, as their design for the 1-h scenario was relatively brief, this is unsurprising given their previously stated views on awareness assist.

\subsection{Comparison of Groups' Handback Designs}

Each group requested a way of visualizing the state of automation and its capabilities. Learner drivers suggested that the car presented its proposed future intentions, intermediates suggested an HUD that showed that the car could detect other vehicles, and the advanced group favored a simpler design consisting of a traffic light system on how risky it is to activate automation given current infrastructure and road condition. This kind of information could enable drivers to calibrate trust with automation so that they can assess whether they can rely on automation prior to activation, a concept well reported across research into how operators use automation [12, 13]. Both the learner and advanced group requested a mode change either on the HDD or HUD for clear awareness that the automation is in control, which 
addresses the problem of mode error that may come about through interactions with automation [15-17].

Intermediate drivers requested more strategic information prior to handback such as a confirmation of destination and junction, a display to show how long the system can be automated for, and other cues such as road signals to show that automation can be activated.

\subsection{DSA and C/HAV Handover and Handback}

Revisiting Salmon et al.'s recommendations in light of DSA [27], a number of comments reflected a need to tailor interactions to drivers. Quotes such as “you don't want it to say too much to you, you know like a voicemail message, it takes forever to get the information you need" (intermediate group, participant 5) indicate a need for information to be well tailored and efficiently delivered to the driver during transactions. Another example of addressing the DSA recommendations is the use of customizable interactions-a recurring theme throughout all focus groups.

Differences across groups provide an indication that driver schemata vary across skill groups, and each requires a tailored approach to C/HAV handover and handback. Examples include the expression of favor toward HUDs and HDDs during handover assist in both learner and intermediate drivers when compared to advanced drivers. As illustrated in previous research, advanced drivers may possess schemata that allow them to raise their own SA more readily than their less experienced counterparts [25, 29].

As a final example of an insight of applications of DSA in $\mathrm{C} / \mathrm{HAV}$ interactions, many drivers across skill groups requested a handback display that presents the driver with the performance, awareness and the future plans of the automated system prior to the driver relinquishing control. Access to information such as this, at this particular time, indicates how both driver and automation can possess different, but compatible, SA which is then communicated at a specific time point to facilitate decision making of driversi.e., whether to activate automation $[25,30]$.

These focus groups indicate that DSA, when applied to $\mathrm{C} / \mathrm{HAV}$ handover and handback, seems to address a number of drivers' recommendations for design — this may be in part due to its ability to address safety, efficiency and tailored designs toward individual requirements and the level of skill [27].

\subsection{Application and Future Development}

The designs generated in these focus groups serve as conceptual inspiration for future designs that want to address driver needs and requirements, while ensuring a high level of usability. As automation in any field is complex, multi-layered and ever-changing, it must be noted that these designs were generated away from specific technical or legal guidelines. It is therefore advised to implement parts of these handover concepts as suited to research and design requirements to adapt to the user and the technical framework in which it is to be applied to. However, the designs merit is found within the innovative design process that drivers with a range of experiences have taken part in.

To build upon and verify the proposed driver-generated designs (or select elements of these designs), simulator or track and road testing should be performed. The authors recommend reading Clark, Stanton and Revell's [2] assessment of vocal handover strategies which measured:

- Time to takeover.

- Behavioral metrics (lateral/longitudinal control).

- Workload.

- System usability.

- System acceptance.

Further considerations could also be made such as:

(1) System trust assessments [68].

(2) SA (e.g., via eye tracking) [69].

As the field of automotive automation progresses, proposed concepts in this study should be applied and assessed in accordance with designers' current technical and legal framework.

\subsection{Limitations}

As a focus group study, the designs presented represent the approaches taken between groups, which may vary between individual groups regardless of driver-experience category. As an example, the learner group preferred to list out multiple ideas and then debate them, whereas the intermediate group agreed on each element prior to moving on to the next stage. Further, the amount of disagreement varied from group to group, with advanced drivers showing the most disagreement regarding individual solutions, this leads to variation in the groups' abilities to converge on an agreed solution. In response to disagreements, the groups decided on methods of customization.

\section{Conclusions}

This study explored how drivers of differing skill levels approached the handover problem through the use of handover HMIs. HMI solutions for the automation-to-driver 
transition of control from three focus groups (learner, intermediate and advanced drivers) were presented. Additionally, amendments for shorter time out-of-the-loop and three solutions for the driver-to-automation transition of control were outlined. As predicted, advanced drivers showed a preference for limited information in awareness-assist interfaces and generally preferred not to rely on HDDs and HUDs for transitions, whereas learner and intermediate drivers requested more information to guide them through the handover using multimodal approaches.

Customization of handover protocol was a common theme throughout the discussions involving changes to alert times and changes to modalities for the display of information. Innovative designs for handover and handback were created including surround cameras and augmented traffic situation (learner group), sophisticated timing systems (intermediate group) and ghosting control of the vehicle prior to handover (advanced group). When addressing the handback, factors such as calibrating trust $[12,13]$ could be assisted by providing the driver-detailed information about automation performance and intentions.

This study provides researchers and designers with ideas for the transition of control in non-critical scenarios, as well as an appreciation of how this may differ with greater driving experience. Implementing designs to accommodate for new insights into distributed situation awareness shows that tailoring the handover toward individual requirements in the driving task is of great importance [27]. Further, as drivers of differing skill vary based on attentional resources [33] and capability to develop and maintain SA [29], it is important to address this factor when considering handover HMI designs. Further work should explore the role of customization for application to C/HAV design - however, care must be paid as to what information remains safety-critical during transitions of control and responsibility.

Acknowledgements This work was supported by Jaguar Land Rover and the UK-EPSRC Grant EP/N011899/1 as part of the jointly funded Towards Autonomy: Smart and Connected Control (TASCC) Programme.

\section{Compliance with Ethical Standards}

Conflict of interest On behalf of all the authors, the corresponding author states that there is no conflict of interest.

Open Access This article is distributed under the terms of the Creative Commons Attribution 4.0 International License (http://creativeco mmons.org/licenses/by/4.0/), which permits unrestricted use, distribution, and reproduction in any medium, provided you give appropriate credit to the original author(s) and the source, provide a link to the Creative Commons license, and indicate if changes were made.

\section{References}

1. SAE International: Taxonomy and definitions for terms related to on-road motor vehicle automated driving systems. SAE Moblus. http://standards.sae.org/j3016_201401/ (2014). Accessed 16 Jan 2014

2. Clark, J.R., Stanton, N.A., Revell, K.M.A.: Conditionally and highly automated vehicle handover: a study exploring vocal communication between two drivers. Transp. Res. Part F Traffic Psychol. Behav. (2019). https://doi.org/10.1016/j. trf.2018.06.008

3. Kyriakidis, M., de Winter, J.C., Stanton, N.A., et al.: A human factors perspective on automated driving. Theor. Issues Ergon. Sci. 41, 1-27 (2017)

4. Audi: Audi A8-Audi AI traffic jam pilot. Audi Technology Portal. https://www.audi-technology-portal.de/en/electrics-elect ronics/driver-assistant-systems/audi-a8-audi-ai-traffic-jam-pilot (2019). Accessed 24 Jan 2019

5. Bueno, M., Dogan, E., Hadj Selem, F., et al.: How different mental workload levels affect the take-over control after automated driving. In: IEEE 19th International Conference on Intelligent Transportation Systems, IEEE, Rio de Janeiro, 1-4 November 2016

6. Molesworth, B.R., Estival, D.: Miscommunication in general aviation: the influence of external factors on communication errors. Saf. Sci. 73, 73-79 (2015)

7. Thomas, M.J., Schultz, T.J., Hannaford, N., et al.: Failures in transition: learning from incidents relating to clinical handover in acute care. J. Healthc. Qual. 35(3), 49-56 (2013)

8. Morgan, P., Alford, C., Parkhurst, G.: Handover Issues in Autonomous Driving: A Literature Review. University of the West of England, Bristol (2016)

9. Endsley, M.R., Kiris, E.O.: The out-of-the-loop performance problem and level of control in automation. Hum. Factors 37(2), 381-394 (1995)

10. Banks, V.A., Eriksson, A., O’Donoghue, J., et al.: Is partially automated driving a bad idea? observations from an on-road study. Appl. Ergon. 68, 138-145 (2018)

11. Banks, V.A., Stanton, N.A.: Keep the driver in control: automating automobiles of the future. Appl. Ergon. 53, 389-395 (2016)

12. Lee, J.D., See, K.A.: Trust in automation: designing for appropriate reliance. Hum. Factors 46(1), 50-80 (2004)

13. Walker, G.H., Stanton, N.A., Salmon, P.: Trust in vehicle technology. Int. J. Veh. Des. 70(2), 157-182 (2016)

14. de Winter, J.D., Stanton, N.A., Price, J.S., et al.: The effects of driving with different levels of unreliable automation on selfreported workload and secondary task performance. Int. J. Veh. Des. 70(4), 297-324 (2016)

15. Sarter, N.B., Woods, D.D.: How in the world did we ever get into that mode? mode error and awareness in supervisory control. Hum. Factors 37(1), 5-19 (1995)

16. Sarter, N.B., Woods, D.D., Billings, C.E.: Automation Surprises. Handbook of Human Factors and Ergonomics, 2nd edn, pp. 1926-1943. Wiley, New York (1997)

17. Stanton, N.A., Dunoyer, A., Leatherland, A.: Detection of new in-path targets by drivers using Stop \& Go Adaptive Cruise Control. Appl. Ergon. 42(4), 592-601 (2011)

18. Horswill, M.S., McKenna, F.P.: Drivers' hazard perception ability: situation awareness on the road. In: Tremblay, S., Banbury, S. (eds.) A Cognitive Approach to Situation Awareness: Theory and Application, pp. 155-175. Ashgate, Aldershot (2004)

19. Jentsch, F., Barnett, J., Bowers, C.A., et al.: Who is flying this plane anyway? what mishaps tell us about crew member role assignment and air crew situation awareness. Hum. Factors 41(1), 1-14 (1999) 
20. Gold, C., Körber, M., Lechner, D., et al.: Taking over control from highly automated vehicles in complex traffic situations: the role of traffic density. Hum. Factors 58(4), 642-652 (2016)

21. Endsley, M.R.: Toward a theory of situation awareness in dynamic systems. Hum. Factors 37(1), 32-64 (1995)

22. Stanton, N.A., Stewart, R., Harris, D., et al.: Distributed situation awareness in dynamic systems: theoretical development and application of an ergonomics methodology. Ergonomics 49(12-13), 1288-1311 (2006)

23. Stanton, N.A., Salmon, P.M., Rafferty, L.A., et al.: Human Factors Methods: A Practical Guide for Engineering and Design. CRC Press, Boba Raton (2017)

24. Sorensen, L.J., Stanton, N.A.: Keeping it together: the role of transactional situation awareness in team performance. Int. J. Ind. Ergon. 53, 267-273 (2016)

25. Walker, G.H., Stanton, N.A., Kazi, T.A., et al.: Does advanced driver training improve situational awareness. Appl. Ergon. 40(4), 678-687 (2009)

26. Stanton, N.A., Marsden, P.: From fly-by-wire to drive-by-wire: safety implications of automation in vehicles. Saf. Sci. 24(1), 35-49 (1996)

27. Salmon, P.M., Stanton, N.A., Jenkins, D.P.: Distributed Situation Awareness: Theory, Measurement and Application to Teamwork. CRC Press, Boba Raton (2017)

28. Neisser, U.: Cognition and Reality. WH Freeman and Company, San Francisco (1976)

29. Bainbridge, L.: Forgotten alternatives in skill and work-load. Ergonomics 21(3), 169-185 (1978)

30. Stanton, N.A., Walker, G.H., Young, M.S., et al.: Changing drivers' minds: the evaluation of an advanced driver coaching system. Ergonomics 50(8), 1209-1234 (2007)

31. Young, M.S., Stanton, N.A.: Attention and automation: new perspectives on mental underload and performance. Theor. Issues Ergon. Sci. 3(2), 178-194 (2002)

32. Young, M.S., Stanton, N.A.: Malleable attentional resources theory: a new explanation for the effects of mental underload on performance. Hum. Factors 44(3), 365-375 (2002)

33. Young, M.S., Stanton, N.A.: What's skill got to do with it? vehicle automation and driver mental workload. Ergonomics 50(8), 1324-1339 (2007)

34. Gopher, D., Kimchi, R.: Engineering psychology. Annu. Rev. Psychol. 40(1), 431-455 (1989)

35. Mayhew, D.R., Simpson, H.M.: The Role of Driving Experience: Implications for Training and Licensing of New Drivers. Insurance Bureau of Canada, Toronto (1995)

36. Quimby, A.R., Maycock, G., Carter, I.D., et al.: Perceptual Abilities of Accident Involved Drivers. Wokingham Transport and Road Research Laboratory, Wokingham (1986)

37. Evans, L.: Traffic Safety. Science Serving Society, Bloomfield Hills (2004)

38. Körber, M., Gold, C., Lechner, D., et al.: The influence of age on the take-over of vehicle control in highly automated driving. Transp. Res. Part F Traffic Psychol. Behav. 39, 19-32 (1989)

39. Mirnig, A.G., Gärtner, M., Laminger, A., et al.: Control transition interfaces in semiautonomous vehicles: a categorization framework and literature analysis. In: Proceedings of the 9th International Conference on Automotive User Interfaces and Interactive Vehicular Applications, ACM, New York, 24-27 September 2017

40. Walch, M., Lange, K., Baumann, M., et al.: Autonomous driving: investigating the feasibility of car-driver handover assistance. In: Proceedings of the 7th International Conference on Automotive User Interfaces and Interactive Vehicular Applications, ACM, New York, 11-18 September 2015

41. Walch, M., Mühl, K., Kraus, J., et al.: From car-driver-handovers to cooperative interfaces: visions for driver-vehicle interaction in automated driving. In: Meixner, G., Müller, C. (eds.): Automotive User Interfaces, pp. 273-294. Springer, Berlin (2017)

42. Petermeijer, S., Bazilinskyy, P., Bengler, K., et al.: Take-over again: investigating multimodal and directional TORs to get the driver back into the loop. Appl. Ergon. 62, 204-215 (2017)

43. Borojeni, S.S., Chuang, L., Heuten, W., et al.: Assisting drivers with ambient take-over requests in highly automated driving. In: Proceedings of the 8th International Conference on Automotive User Interfaces and Interactive Vehicular Applications, ACM, New York, 24-26 October 2016

44. Forster, Y., Naujoks, F., Neukum, A.: Your turn or my turn: design of a human-machine interface for conditional automation. In: Proceedings of the 8th International Conference on Automotive user interfaces and interactive vehicular applications, ACM, New York, 24-26 October 2016

45. Politis, I., Brewster, S., Pollick, F.: Language-based multimodal displays for the handover of control in autonomous cars. In: Proceedings of the 7th International Conference on Automotive User Interfaces and Interactive Vehicular Applications, ACM, New York, 3-10 September 2015

46. Naujoks, F., Forster, Y., Wiedemann, K., et al.: A human-machine interface for cooperative highly automated driving. In: Stanton, N.A., Landry, S., Bucchianico, G.D., et al. (eds.): Advances in Human Aspects of Transportation, pp. 585-595. Springer, Berlin (2017)

47. Naujoks, F., Neukum, A.: Specificity and timing of advisory warnings based on cooperative perception. In: The Proceedings of Mensch \& Computer 2014, pp. 229-238. De Gruyter, Berlin (2014)

48. Patterson, E.S., Woods, D.D.: Shift changes, updates, and the oncall architecture in space shuttle mission control. Comput. Support. Coop. Work 10(3-4), 317-346 (2001)

49. Sanders, E.B.N.: From user-centered to participatory design approaches. In: Frascara, J. (ed): Design and the Social Sciences, pp. 18-25. CRC Press, London (2003)

50. Spinuzzi, C.: Losing by expanding: corralling the runaway object. J. Bus. Tech. Commun. 25(4), 449-486 (2011)

51. Bonett, M.: Personalization of web services: opportunities and challenges. Ariadne. http://www.ariadne.ac.uk/issue28/personaliz ation/?ref=Sawos.org (2019). Accessed 24 Jan 2019

52. Brennanm, P.M., Adelman, J.: Speech based status and control user interface customisable by the user. U.S. Patent 7,333,933, 19 February 2008

53. The Oxford English Dictionary: Customize. Lexico. https:// en.oxforddictionaries.com/definition/customize (2019). Accessed 24 Jan 2019

54. The Oxford English Dictionary: Personalize. Lexico. https ://en.oxforddictionaries.com/definition/personalize (2019). Accessed 24 Jan 2019

55. Rabiee, F.: Focus-group interview and data analysis. Proc. Nutr. Soc. 63(4), 655-660 (2004)

56. Institute of Advanced Motorists: We make better riders and drivers. IAM Roadsmart. https://www.iamroadsmart.com/ (2019). Accessed 24 Jan 2019

57. The Royal Society for the Prevention of Accidents: Accidents don't have to happen. ROSPA. https://www.rospa.com/ (2019). Accessed 24 Jan 2019

58. Krueger, R.A., Casey, M.A.: Designing and conducting focus group interviews. Illinois Higher Education Centre. https:// www.eiu.edu/ihec/Krueger-FocusGroupInterviews.pdf (2019). Accessed 24 Jan 2019

59. Krueger, R.A., Casey, M.A.: Focus Groups: A Practical Guide for Applied Research. SAGE Publications, California City (2015) 
60. Health and Safety Executive: How to organise and run focus groups. HSE. http://www.hse.gov.uk/stress/assets/docs/focus groups.pdf (2019). Accessed 24 Jan 2019

61. McHugh, M.L.: Interrater reliability: the kappa statistic. Biochem. Med. 22(3), 276-282 (2012)

62. Oviatt, S.: Multimodal interactive maps: designing for human performance. Hum. Comput. Interact. 12(1), 93-129 (1997)

63. Vitense, H.S., Jacko, J.A., Emery, V.K.: Multimodal feedback: an assessment of performance and mental workload. Ergonomics 46(1-3), 68-87 (2003)

64. Bazilinskyy, P., de Winter, J.: Auditory interfaces in automated driving: an international survey. PeerJ. Comput. Sci. 1, e13 (2015)

65. Bazilinskyy, P., Petermeijer, S.M., Petrovych, V., et al.: Take-over requests in highly automated driving: a crowdsourcing survey on auditory, vibrotactile, and visual displays. Transp. Res. Part F Traffic Psychol. Behav. 56, 82-98 (2015)

66. Adamson, S., Lardner, R., Miller, S.: Safe communication at shift handover: setting and implementing standards. IChemE Symp. Ser. 138, 411-424 (1999)

67. Lewis, P.M., Swaim, D.J.: Effect of a 12-hour/day shift on performance. In: 1988 IEEE Fourth Conference on Human Factors and Power Plants. IEEE, Monterey CA, 5-9 June 1988

68. Jian, J.Y., Bisantz, A.M., Drury, C.G.: Foundations for an empirically determined scale of trust in automated systems. Int. J. Cogn. Ergon. 4(1), 53-71 (2000)

69. De Winter, J.C.F., Eisma, Y.B., Cabrall, C.D.D., et al.: Situation awareness based on eye movements in relation to the task environment. Cogn. Technol. Work 21(1), 99-111 (2019) 